\title{
Efeito de épocas da colheita sobre características agronômicas de etnovariedades da mandioca
}

A mandioca é um dos alimentos mais conhecidos no Brasil e seu cultivo é muito importante, especialmente para a agricultura familiar. Suas raízes tuberosas, ricas em carboidratos, podem ser colhidas em larga faixa de tempo, dependendo da etnovariedade e da região de cultivo, indicando, portanto, a necessidade de se definir a melhor época de colheita, visando aumento da produtividade e maximização da área agrícola. Diante disso, o objetivo deste trabalho foi avaliar o efeito de quatro épocas de colheita (seis, oito, dez e doze meses pós-plantio) sobre características agronômicas de quatro etnovariedades de mandioca (Cacau branca, Cacau roxa, Cacau amarela e Mandioca pão), nas condições edafoclimáticas do município de Alta Floresta, Mato Grosso, Brasil. O delineamento experimental fo em blocos casualizados, com quatro repetições em um esquema de parcelas (etnovariedades) e subparcelas (épocas de colheita). Em cada época de colheita foram avaliados os descritores agronômicos: produtividade da parte aérea, produtividade de raízes tuberosas, índice de colheita, número de raízes por planta, comprimento e diâmetro médio das raízes. Os dados foram submetidos à análise de variância e ao ajuste de modelo de regressão polinomial. Os resultados demonstraram que a época de colheita influenciou as características agronômicas das quatro etnovariedades de mandioca avaliadas. As etnovariedades Cacau roxa e Cacau amarela apresentaram pico de produtividade de raízes tuberosas aos oito e dez meses pós-plantio, respectivamente. Já a Cacau branca e Mandioca pão apresentam-se mais produtivas aos 12 meses, indicando que a permanência das plantas no campo proporcionou incremento na produtividade e diâmetro das raízes, além de maior índice de colheita e, portanto, são boas opções para o agricultor familiar mato-grossense.

\section{Effect of harvest time on agronomic characteristic of cassava landraces}

\begin{abstract}
The cassava is a popular food in Brazil; the crop is especially important for familiar agriculture. The tuberous roots have abundant carbohydrates, and they can be harvest over a long period, depending on landraces and growing region. Then, it is necessary to define the best harvest time, aiming at increasing productivity and maxing the agriculture area. Here, our objective was evaluated the effect of four harvest time (six, eight, ten, and twelve months after planting) on agronomic characteristics of four cassava landraces (Cacau branca, Cacau roxa, Cacau amarela and Mandioca pão) under the climatic conditions edaphoclimatic in Alta Floresta, Mato Grosso state, Brazil. The experimental design was in randomized block with four replications, following plot scheme (landraces) and subplots (harvest time). For each harvest time, we evaluated following agronomic descripts: aerial part productivity, tuberous root productivity, harvest index, number of roots per plant, length and average diameter of the roots. Date were used to analysis of variance and adjustment of the polynomial regression model. Our results presented that the harvest time influenced the agronomic characteristics of the cassava landraces. The landraces Cacau roxa and Cacau Amarela presented greater productivity of roots at eight and ten months after planting, respectively. Cacau branca and Mandioca Pão were more productive at twelve months, suggesting that the permanence of plants in the field increases productivity, root diameter and harvest index. Therefore, it is good options for the family farmer from Mato Grosso.
\end{abstract}

Keywords: Agronomic descripts; Manihot esculenta; Aerial part; Productivity; Tuberous roots.

Topic: Experimentação Agrícola

Reviewed anonymously in the process of blind peer.
Received: 09/03/2020

Approved: 11/04/2020
Eliane Cristina Moreno de Pedri (iD

Universidade do Estado de Mato Grosso, Brasil http://lattes.cnpq.br/9596235243976750

http://orcid.org/0000-0002-7044-581X elicmbio@gmail.com

Ana Aparecida Bandini Rossi (iD) Universidade do Estado de Mato Grosso, Brasil http://lattes.cnpq.br/2734433144153549 http://orcid.org/0000-0002-8318-5375 anabanrossi@unemat.br

Eulalia Soler Sobreira Hoogerheide (id) Embrapa Agrossilvipastoril, Brasil http://lattes.cnpq.br/8497096021170936 http://orcid.org/0000-0003-0944-3898 eulalia.hoogerheide@embrapa.br

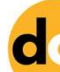

DOI: 10.6008/CBPC2179-6858.2020.003.0003
Auana Vicente Tiago (iD)

Universidade do Estado de Mato Grosso, Brasi http://lattes.cnpq.br/3112795576497501 http://orcid.org/0000-0001-9556-9491 auanabio@hotmail.com

Elisa dos Santos Cardoso (iD

Universidade do Estado de Mato Grosso, Brasil http://lattes.cnpq.br/7863449442902495 http://orcid.org/0000-0001-9477-1743 elisabyo@gmail.com

Kelli Évelin Müller Zortéa (D)

Universidade do Estado de Mato Grosso, Brasil http://lattes.cnpq.br/7140876715622617 http://orcid.org/0000-0003-0545-6130 kellimuller@hotmail.com
Vinicius Delgado da Rocha (id Universidade Federal de Viçosa, Brasil http://lattes.cnpq.br/1145432535640113 http://orcid.org/0000-0001-7336-7223 viniciusdelgado123@hotmail.com

\section{Oscar Mitsuo Yamashita (D)}

Universidade do Estado de Mato Grosso, Brasil http://lattes.cnpq.br/1761470950121024 http://orcid.org/0000-0001-6715-626X yama@unemat.br
Referencing this:

PEDRI, E. C. M.; ROSSI, A. A. B.; HOOGERHEIDE, E. S. S.; TIAGO, A. V.; CARDOSO, E. S.; ZORTÉA, K. É. M.; ROCHA, V. D.; YAMASHITA, O. M.. Efeito de épocas da colheita sobre características agronômicas de etnovariedades da mandioca. Revista Ibero Americana de Ciências Ambientais, v.11, n.3, p.20-31, 2020. DOI:

http://doi.org/10.6008/CBPC2179-6858.2020.003.0003 


\section{INTRODUÇÃO}

A mandioca (Manihot esculenta Crantz., Euphorbiaceae) é uma importante fonte de carboidratos que se destaca na alimentação humana e animal, além de apresentar distintos usos nas agroindústrias de processamento. Suas raízes tuberosas são o principal produto econômico da planta, porém a parte aérea (caule, pecíolos e folhas), pelo alto teor de vitaminas e minerais, é utilizada na produção de silagem para alimentação animal (MELO et al., 2007; OLIVEIRA et al., 2012; PEREIRA et al., 2018; RIBEIRO et al., 2019).

No Brasil, a produção da mandioca é predominantemente realizada pela agricultura familiar pela facilidade de propagação, adaptação a condições adversas de clima e solo, resistência às pragas e doenças, potencial produtivo e baixo custo de produção (ALBUQUERQUE et al., 2009; CHIELLE et al., 2009; PESTANA et al., 2015), podendo ser produzida, eficientemente, em pequena escala (FAO, 2013). Desta forma, o cultivo da mandioca contribui ainda mais com a agricultura familiar que, de acordo com Cardoso et al. (2018) é um dos principais segmentos do espaço agrário, produzindo alimentos em maior quantidade, qualidade e diversidade que o agronegócio, ganhando importância econômica, social e política.

O desenvolvimento da planta da mandioca, bem como a produtividade das raízes é afetado por condições ambientais específicas (clima e solo) durante o seu ciclo vegetativo. Apesar de se adaptar bem a condições edafoclimáticas, a espécie apresenta ampla interação genótipo x ambiente, indicando que dificilmente as etnovariedades irão apresentar desempenho agronômico semelhante em ambientes distintos. Por isso, a caracterização agronômica da mandioca, por meio de descritores quali e quantitativos, é importante e necessária para a seleção de variedades mais adaptadas as regiões específicas e mais estáveis na sua produção (MORETO et al., 2016; TEIXEIRA et al., 2017).

A mandioca é uma espécie perene cujos tubérculos podem ser colhidos em larga faixa de tempo, variando de 6 a 24 meses, dependendo da etnovariedade, da região de cultivo, da utilização e da demanda de mercado (ALBUQUERQUE, 2003). Por isso, é importante para o agricultor definir a melhor época de colheita, pois quando colhidas muito cedo há redução da produtividade, pois estas não atingiram seu nível máximo de acúmulo de matéria seca, e quando mantidas em campo por período prolongado, aumenta-se o índice de podridão das raízes e o teor de fibras, afetando assim a qualidade das mesmas (PONTE, 2008).

A determinação do tempo de colheita apropriado e sua relação com as características agronômicas são fundamentais para a recomendação e incorporação de variedades de mandioca nos sistemas de produção (LESSA et al., 2019). Como destaca Soares (2011) definir a melhor época de colheita possibilita ao agricultor selecionar as etnovariedades que apresentam maior adaptação e rentabilidade local, maximizando o uso da área agrícola e minimizando problemas com pragas e doenças. Diante deste contexto, o objetivo deste estudo foi avaliar o efeito de quatro épocas de colheita sobre características agronômicas de quatro etnovariedades de mandioca, nas condições edafoclimáticas do município de Alta Floresta, Mato Grosso, Brasil. 


\section{MATERIAIS E MÉTODOS}

O experimento foi conduzido na Chácara Nossa Senhora Aparecida, Comunidade Central, zona rural do município de Alta Floresta, Mato Grosso, a 9 $57^{\prime} 04^{\prime \prime}$ S e $56^{\circ} 05^{\prime} 55^{\prime \prime} \mathrm{W}, 304 \mathrm{~m}$ de altitude (Figura 1). A área experimental apresenta Latossolo Vermelho-Amarelo Distrófico de textura argilosa de acordo com o triângulo textural (EMBRAPA, 2013).

O clima da região é classificado como Am, com estação chuvosa e seca, temperatura média entre 23 e $29^{\circ} \mathrm{C}$ e precipitação anual variando entre 2500 e $3100 \mathrm{~mm}$ (ALVARES et al., 2013). Os dados meteorológicos obtidos durante a condução do experimento se encontram na Figura 2, sendo registradas temperaturas médias máximas e mínimas de $32{ }^{\circ} \mathrm{C}$ e $21^{\circ} \mathrm{C}$, respectivamente, com precipitação média anual de $2169 \mathrm{~mm}$.

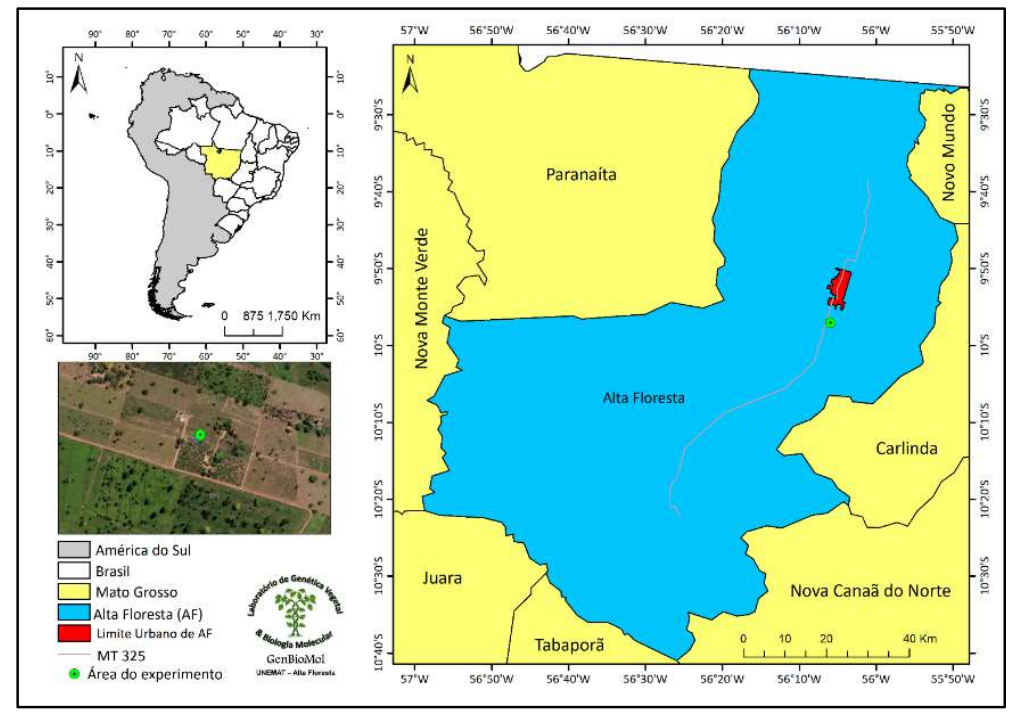

Figura 1: Localização geográfica da área experimental, situada na zona rural do município de Alta Floresta, Mato Grosso, Brasil.

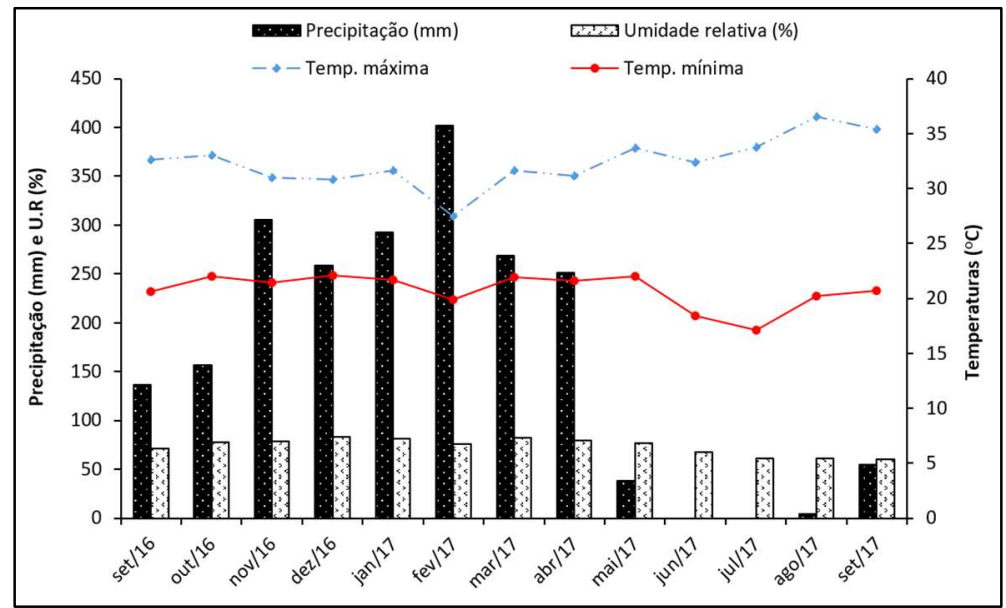

Figura 2: Médias de precipitação $(\mathrm{mm})$, umidade relativa do ar (U.R \%) e temperaturas máximas e mínimas $\left({ }^{\circ} \mathrm{C}\right)$, coletadas entre setembro de 2016 a setembro de 2017, na Estação Meteorológica da UNEMAT, Campus de Alta Floresta, Mato Grosso.

A análise química e física do solo, baseada em amostras coletadas em profundidade de 0 a $10 \mathrm{~cm}$, foi realizada no Laboratório de Análise de Solos, Adubos e Foliar (LASAF) da UNEMAT, Campus de Alta Floresta/MT (Tabela 1). A área experimental foi preparada por meio de aração, gradagem niveladora, alinhamento e abertura manual das covas. As etnovariedades avaliadas foram escolhidas com base em 
resultados experimentais obtidos por Tiago (2016), sendo elas: Cacau branca (CB), Cacau roxa (CR), Cacau amarela (CA) e Mandioca pão (MP), todas consideradas aptas para o cultivo na região.

Tabela 1: Resultado da análise química e física do solo da área experimental.

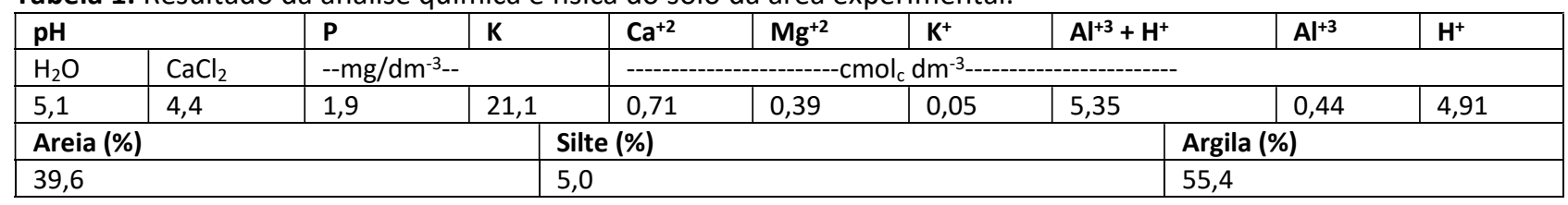

As etnovariedades foram plantadas em setembro de 2016, em uma área total de $1200 \mathrm{~m}^{2}$, utilizandose manivas de 2 a $3 \mathrm{~cm}$ de diâmetro, com 5 a 7 gemas e comprimento médio de $20 \mathrm{~cm}$, obtidas do terço médio de hastes de plantas com doze meses de idade. 0 espaçamento adotado foi 1,0 m entre plantas e 1,2 $\mathrm{m}$ entre linhas. $\mathrm{O}$ controle de plantas invasoras foi realizado por meio de tratos culturais ao longo da realização do experimento.

O delineamento experimental foi em blocos casualizados, com quatro repetições e os tratamentos arranjados segundo o esquema de parcelas e subparcelas, sendo as parcelas constituídas por quatro etnovariedades ( $C B, C R, C A$ e MP) e as subparcelas por quatro épocas de colheita (seis, oito, dez e doze meses pós-plantio).

Na colheita manual da mandioca, foram avaliadas 24 plantas de cada etnovariedade em cada época de colheita, seguindo os descritores agronômicos propostos por Fukuda \& Guevara (1998), sendo eles: Produtividade da parte aérea (PPA): pesagem de toda a planta, expresso em $\mathrm{t} \mathrm{ha}{ }^{-1}$; Produtividade de raízes tuberosas (PRT): pesagem de todas as raízes tuberosas produzidas, em t ha ${ }^{-1}$; Índice de colheita (IC): expresso em \%, obtido por meio da relação entre o peso das raízes tuberosas e o peso total das plantas (raízes + parte aérea) (VÍTOR et al., 2016); Número de raízes por planta (NRP); Comprimento médio das raízes (CMR): expresso em cm e Diâmetro médio das raízes (DMR): expresso em $\mathrm{cm}$.

Os dados foram submetidos à análise de variância (ANOVA) e as médias comparadas pelo teste de Tukey a 5\% de probabilidade. Para o fator época de colheita, foram ajustadas regressões polinomiais, sendo que a escolha do modelo foi feita com base no maior valor do coeficiente de determinação $\left(R^{2}\right)$. As análises estatísticas foram realizadas utilizando o programa estatístico Genes, versão 2018.23 (CRUZ, 2016).

\section{RESULTADOS E DISCUSSÃO}

De acordo com a análise de variância, a época de colheita influenciou todas as características agronômicas avaliadas apresentando efeito significativo $(p<0,05)$ na interação entre etnovariedades e épocas de colheita (Tabela 2).

As quatro etnovariedades de mandioca estudadas apresentaram diferenças significativas para a característica produtividade da parte aérea apenas aos seis meses pós-plantio (Tabela 3), sendo que a Mandioca pão obteve valores superior às demais. Portanto, nas condições experimentais, a etnovariedade MP desenvolveu maior volume de copa, incluindo ramos e folhas. Isso é importante para maior conversão de energia luminosa para acúmulo de reservas, tornando-a potencialmente mais produtiva. Além disso, a 
possibilidade de aproveitamento da parte aérea (caule, pecíolos e folhas), principalmente para alimentação animal (in natura, silagem ou feno), torna a avaliação de produção de massa verde importante (CHIELLE et al., 2009).

Tabela 2: Resumo da análise de variância das características: produtividade da parte aérea (PPA; $t$ ha $\left.{ }^{-1}\right)$, produtividade de raízes tuberosas (PRT; $t \mathrm{ha}^{-1}$ ), índice de colheita (IC\%), número de raízes por planta (NRP), comprimento (CMR; $\mathrm{cm}$ ) e diâmetro médio das raízes (DMR; $\mathrm{cm}$ ) de etnovariedades cultivadas e colhidas em diferentes épocas.

\begin{tabular}{|c|c|c|c|c|c|c|c|}
\hline \multirow[t]{2}{*}{ FV } & \multirow[t]{2}{*}{ GL } & \multicolumn{5}{|c|}{ Quadrados Médios } & \multirow[b]{2}{*}{ DMR } \\
\hline & & PPA & PRT & IC\% & NRP & CMR & \\
\hline ETNO & 3 & $20,89^{\text {ns }}$ & $457,63^{* *}$ & $746,54^{* *}$ & $1,57^{\mathrm{ns}}$ & $357,26^{* *}$ & $26,44^{* *}$ \\
\hline EC & 3 & $367,91^{* *}$ & $49,11^{* *}$ & $1831,26^{* *}$ & $114,88^{* *}$ & $4,22^{\mathrm{ns}}$ & $4,98^{* *}$ \\
\hline ETNO*EC & 9 & $15,59^{* *}$ & $29,70^{* *}$ & $63,08^{*}$ & $9,56^{* *}$ & $12,74^{* *}$ & $0,47^{* *}$ \\
\hline Resíduo & 45 & 5,17 & 6,82 & 27,68 & 2,33 & 2,35 & 0,15 \\
\hline Média & -- & 11,70 & 16,69 & 58,54 & 12,21 & 25,82 & 11,39 \\
\hline C.V (\%) & -- & 19,44 & 15,64 & 8,99 & 12,51 & 5,93 & 3,45 \\
\hline
\end{tabular}

FV: Fonte de variação, GL: Grau de liberdade, ETNO: Etnovariedades, EC: Épocas de colheita, C.V: Coeficiente de variação, ${ }^{\text {ns }},{ }^{*},{ }^{* *}$, Não significativo, significativo a 5 e $1 \%$ de probabilidade, respectivamente, pelo teste $\mathrm{F}$.

Tabela 3: Médias de produtividade da parte aérea $\left(\mathrm{t} \mathrm{ha}^{-1}\right)$ (PPA) de quatro etnovariedades de mandioca em diferentes épocas de colheita.

\begin{tabular}{|l|l|l|l|l|l|}
\hline \multirow{2}{*}{ Etnovariedades } & \multicolumn{2}{|l|}{ Épocas de colheita } & \multicolumn{1}{l|}{} \\
\cline { 2 - 6 } & $\mathbf{6}$ meses & $\mathbf{8}$ meses & $\mathbf{1 0}$ meses & $\mathbf{1 2}$ meses & Média \\
\hline Cacau branca & $15,84 \mathrm{~b}$ & $11,82 \mathrm{a}$ & $7,21 \mathrm{a}$ & $8,06 \mathrm{a}$ & 10,73 \\
\hline Cacau roxa & $17,10 \mathrm{~b}$ & $14,20 \mathrm{a}$ & $7,98 \mathrm{a}$ & $7,90 \mathrm{a}$ & 11,80 \\
\hline Cacau amarela & $16,50 \mathrm{~b}$ & $11,48 \mathrm{a}$ & $9,74 \mathrm{a}$ & $6,31 \mathrm{a}$ & 11,01 \\
\hline Mandioca pão & $22,99 \mathrm{a}$ & $13,11 \mathrm{a}$ & $6,69 \mathrm{a}$ & $10,32 \mathrm{a}$ & 13,28 \\
\hline Média & $\mathbf{1 8 , 1 1}$ & $\mathbf{1 2 , 6 5}$ & $\mathbf{7 , 9 1}$ & $\mathbf{8 , 1 5}$ & - \\
\hline
\end{tabular}

Médias seguidas da mesma letra na coluna não diferem entre si pelo teste Tukey, a $5 \%$ de probabilidade. Diferença mínima significativa (DMS $=4,29$ ).

Entretanto, a superioridade da MP foi verificada apenas aos seis meses pós-plantio. Nas demais colheitas, não se observou diferença entre as etnovariedades. Assim, apesar da superioridade inicial da MP, esta não se manteve nas demais colheitas. Esses resultados ocorrem com certa frequência, pois algumas variedades crioulas podem ter desenvolvido, ao longo do tempo, uma maior capacidade de desenvolvimento inicial das plantas, cuja finalidade é ocupar a área ao seu entorno, evitando-se assim, a matocompetição, que poderia prejudicá-la.

Verificou-se também que a produção da parte aérea da mandioca na primeira avaliação (seis meses pós-plantio) foi superior às demais épocas de colheita para todas as etnovariedades, apresentando neste período, os menores índices de colheita. Cardoso Junior et al. (2005) destacam que o baixo IC, causado pela grande produção de massa verde, pode ser importante quando se objetiva seus usos na alimentação animal, ou em regiões em que ocorram fatores adversos à conservação do material de propagação, como as condições ambientais, pragas e doenças. Portanto, a etnovariedade MP apresenta características que permitem sua exploração para cultivos que visem à utilização de ramos e folhas na alimentação animal.

Naturalmente, as plantas da mandioca tendem a reduzir gradualmente as atividades vegetativas e perdem parcial ou totalmente as folhas em períodos menos chuvosos e em condições de temperaturas mais amenas (PONTE, 2008). Neste estudo foi possível observar efeito quadrático decrescente para produtividade da parte aérea em função das épocas de colheita nas quatro etnovariedades analisadas (Figura 3), indicando que o comportamento desta variável pode ter sido influenciado pelas condições climáticas, visto que as 
maiores médias de PPA foram obtidas aos seis meses (março/2017), período de colheita em que foi observada a maior precipitação média $\left(269 \mathrm{~mm}\right.$ ) e temperaturas mínimas de $22{ }^{\circ} \mathrm{C}$ (Figura 2).

Soares (2011) e Ponte (2008) também observaram resultados semelhantes e relatam que o comportamento de variedades de mandioca, quanto à produtividade de parte aérea, foi condicionado por condições climáticas (baixa precipitação pluvial e temperaturas mínimas).

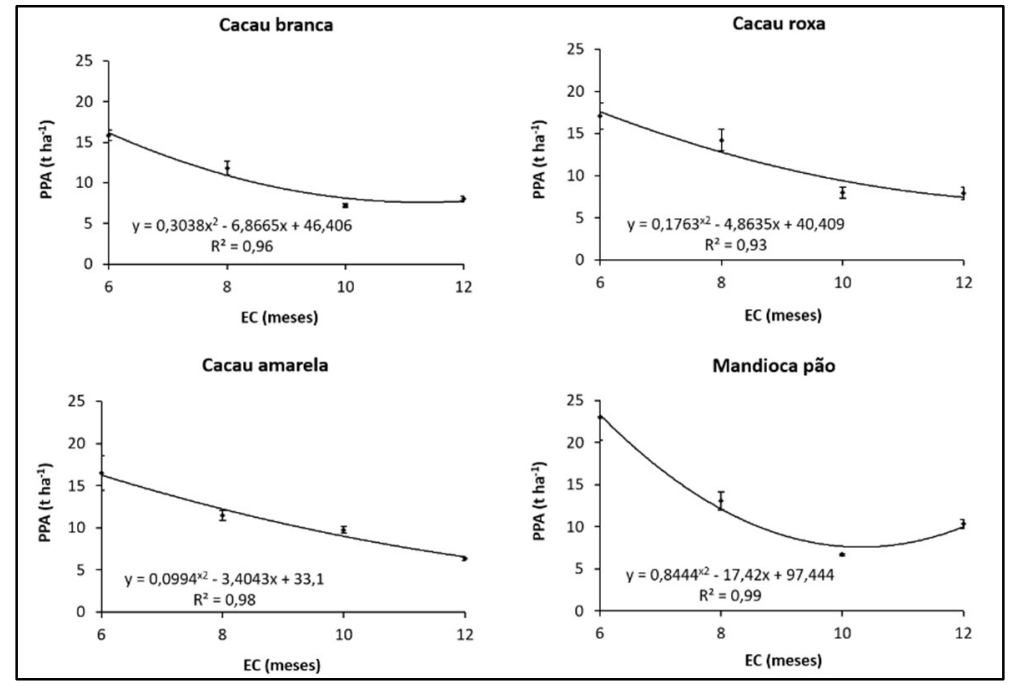

Figura 3: Produtividade da parte aérea da planta (PPA) $\left(\mathrm{t} \mathrm{ha} \mathrm{a}^{-1}\right.$ ) de quatro etnovariedades de mandioca em diferentes épocas de colheita (EC). $\mathbf{\Phi}$ : erro padrão da média.

Quanto à produtividade das raízes tuberosas (PRT), as etnovariedades apresentaram diferenças dentro das épocas de colheita (Tabela 4), sendo, a maior média encontrada de 26,63 t ha ${ }^{-1}$, superior às médias relatadas por Soares et al. (2017) e Vítor et al. (2016), em estudos com etnovariedades locais nos estados da Bahia e Tocantins, demonstrando o potencial de produção das etnovariedades cultivadas na Amazônia Meridional. A alta produtividade das etnovariedades CB, CR e MP também foi observada por Tiago (2016), quando estas se destacaram quanto ao descritor PRT dentre as 17 etnovariedades por ela avaliada.

Tabela 4: Médias da produtividade de raízes tuberosas (PRT) ( $\mathrm{t} \mathrm{ha} \mathrm{H}^{-1}$ ) de quatro etnovariedades de mandioca em diferentes épocas de colheita.

\begin{tabular}{|l|l|l|l|l|l|}
\hline \multirow{2}{*}{ Etnovariedades } & \multicolumn{4}{l|}{ Épocas de colheita } & \\
\cline { 2 - 6 } & $\mathbf{6}$ meses & $\mathbf{8}$ meses & $\mathbf{1 0}$ meses & $\mathbf{1 2}$ meses & Média \\
\hline Cacau branca & $9,65 \mathrm{~b}$ & $11,15 \mathrm{~b}$ & $7,31 \mathrm{~b}$ & $14,32 \mathrm{c}$ & 10,61 \\
\hline Cacau roxa & $18,72 \mathrm{a}$ & $23,84 \mathrm{a}$ & $19,83 \mathrm{a}$ & $20,82 \mathrm{~b}$ & 20,80 \\
\hline Cacau amarela & $11,84 \mathrm{~b}$ & $13,88 \mathrm{~b}$ & $17,48 \mathrm{a}$ & $12,04 \mathrm{c}$ & 13,81 \\
\hline Mandioca pão & $17,85 \mathrm{a}$ & $21,95 \mathrm{a}$ & $19,77 \mathrm{a}$ & $26,63 \mathrm{a}$ & 21,55 \\
\hline Média & $\mathbf{1 4 , 5 2}$ & $\mathbf{1 7 , 7 1}$ & $\mathbf{1 6 , 1 0}$ & $\mathbf{1 8 , 4 5}$ & - \\
\hline
\end{tabular}

Médias seguidas da mesma letra na coluna não diferem entre si pelo teste Tukey, a $5 \%$ de probabilidade. Diferença mínima significativa (DMS $=4,93)$.

A variação na produtividade das raízes de mandioca verificada na primeira avaliação demonstra que a CR e MP foram superiores às demais. Essa tendência se manteve até a colheita realizada aos 12 meses, pois estas produziram praticamente o dobro, indicando maior potencial produtivo e variabilidade genética entre as etnovariedades, confirmando, assim, relatos de Zatarim et al. (2007) quanto ao grau de diferenciação entre os germoplasma brasileiro de mandioca, destacando ainda a importância de estudos regionais que visam à avaliação e seleção de novos materiais. 
As etnovariedades CB e MP apresentaram pico de produtividade de raízes aos doze meses pósplantio. Já a CR aos oito meses e a CA aos dez meses. Portanto, a permanência das plantas no campo não interferiu na produção das raízes da etnovariedade CR, podendo ser colhida aos oito meses pós-plantio, quando apresenta maior rendimento de raízes tuberosas.

Definir a melhor época de colheita para cada etnovariedade pode proporcionar ao agricultor um rápido retorno financeiro, além de não deixar a cultura exposta a riscos ambientais, tais como podridão de raízes e ataques de pragas e doenças. Os autores Ponte (2008), Aguiar et al. (2011), Vítor et al. (2016) e Soares et al. (2017), avaliando épocas de colheita de distintas variedades de mandioca, constataram variação na sua produtividade em função das épocas de colheita. Os autores enfatizam para a importância do desenvolvimento e divulgação de estudos regionais com etnovariedades que apresentem melhor adaptação às condições de cultivo local.

As etnovariedades CB e MP obtiveram um aumento crescente da PRT em função das épocas de colheita, apresentando maiores médias de produtividade (14,32 e 26,63 $\mathrm{t} \mathrm{ha}^{-1}$, respectivamente) aos 12 meses pós-plantio (Figura 4). Portanto, destaca-se a possibilidade de mantê-las por mais tempo no campo visando aumento da produção. Esses resultados concordam com Fialho et al. (2009) que, ao estudarem seis épocas de colheita em variedades de mandioca, também constataram que quanto mais tardia é a colheita, maior a produtividade das raízes. Porém, neste estudo, as etnovariedades CR e CA não seguiram este padrão, pois apresentaram maior produção de raízes antes dos 12 meses.

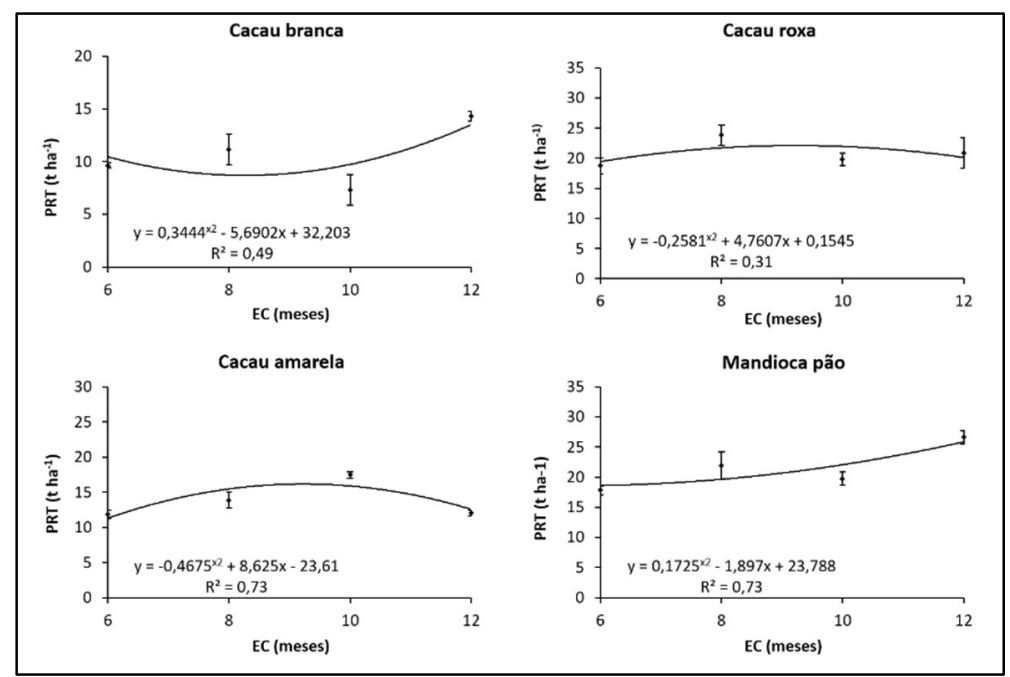

Figura 4: Produtividade das raízes tuberosas (PRT) $\left(\mathrm{t} \mathrm{ha}{ }^{-1}\right)$ de quatro etnovariedades de mandioca em diferentes épocas de colheita. $\mathbf{\Phi}$ : erro padrão da média.

Comparando as etnovariedades, em cada época de colheita, observa-se diferenças para o índice de colheita nas três primeiras épocas de avaliação (Tabela 5), demonstrando variação no comportamento destas, resultado da variabilidade genética e da interação de cada genótipo com o ambiente. Segundo Conceição (1981), valores de IC acima de 60\% são considerados adequados. Neste estudo, a CB apresentou valor adequado (>60\%) aos doze meses pós-plantio, a CA aos dez e doze meses e a CR e MP nas três últimas datas de colheita. 
Tabela 5: Médias do índice de colheita (\%) (IC) de quatro etnovariedades de mandioca em diferentes épocas de colheita.

\begin{tabular}{|l|l|l|l|l|}
\hline \multirow{2}{*}{ Etnovariedades } & Épocas de colheita & $\mathbf{1 0}$ \\
\cline { 2 - 5 } & $\mathbf{6}$ meses & $\mathbf{8}$ meses & $\mathbf{1 0}$ meses & $\mathbf{1 2}$ meses \\
\hline Cacau branca & $37,92 \mathrm{~b}$ & $48,06 \mathrm{~b}$ & $48,77 \mathrm{c}$ & $64,01 \mathrm{a}$ \\
\hline Cacau roxa & $52,38 \mathrm{a}$ & $62,64 \mathrm{a}$ & $71,27 \mathrm{ab}$ & $71,79 \mathrm{a}$ \\
\hline Cacau amarela & $42,30 \mathrm{~b}$ & $54,54 \mathrm{ab}$ & $64,26 \mathrm{~b}$ & $65,60 \mathrm{a}$ \\
\hline Mandioca pão & $44,23 \mathrm{ab}$ & $62,16 \mathrm{a}$ & $74,61 \mathrm{a}$ & $72,11 \mathrm{a}$ \\
\hline
\end{tabular}

Médias seguidas da mesma letra na coluna não diferem entre si pelo teste Tukey, a 5\% de probabilidade. Diferença mínima significativa (DMS $=9,93)$.

A época de colheita influenciou no IC de todas as etnovariedades, sendo observado efeito crescente desta característica em função das épocas de colheita (Figura 5). Em geral, o IC apresenta tendência crescente, ocorrendo, em algumas etnovariedades um pequeno decréscimo aos 12 meses. Andrade (2013) também observou variações do IC em função das épocas de colheita, o que segundo ele, se deve à competição existente entre o desenvolvimento das raízes e da parte aérea.

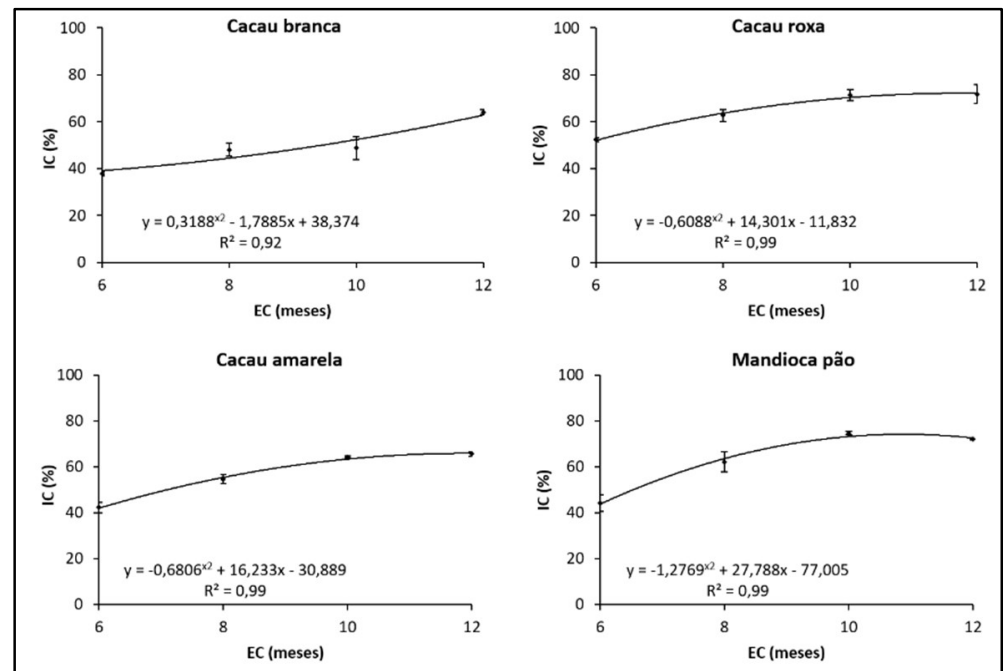

Figura 5: Índice de colheita (IC) (\%) de quatro etnovariedades de mandioca em diferentes épocas de colheita (EC). erro padrão da média.

Quanto ao número de raízes tuberosas por planta, a média foi de 12 para a $C B, C R$ e $C A$ e 13 para a MP (Tabela 6). O número de raízes é, geralmente, definido nos primeiros quatro meses após o plantio, depois disso ocorre o crescimento das mesmas pelo acúmulo de carboidratos (AGUIAR et al., 2011). Gonçalves (2018) destaca ainda que a predição da produção pode ser obtida pelo número de raízes por planta.

Tabela 6: Número médio de raízes por planta (NRP) de quatro etnovariedades de mandioca em diferentes épocas de colheita.

\begin{tabular}{|l|l|l|l|l|}
\hline \multirow{2}{*}{ Etnovariedades } & \multicolumn{4}{l|}{ Épocas de colheita } \\
\cline { 2 - 5 } & $\mathbf{6}$ meses & $\mathbf{8}$ meses & $\mathbf{1 0}$ meses & $\mathbf{1 2}$ meses \\
\hline Cacau branca & $11 \mathrm{a}$ & $12 \mathrm{a}$ & $16 \mathrm{ab}$ & $10 \mathrm{ab}$ \\
\hline Cacau roxa & $10 \mathrm{ab}$ & $14 \mathrm{a}$ & $15 \mathrm{ab}$ & $09 \mathrm{~b}$ \\
\hline Cacau amarela & $08 \mathrm{~b}$ & $12 \mathrm{a}$ & $18 \mathrm{a}$ & $10 \mathrm{ab}$ \\
\hline Mandioca pão & $12 \mathrm{a}$ & $12 \mathrm{a}$ & $14 \mathrm{~b}$ & $12 \mathrm{a}$ \\
\hline
\end{tabular}

Médias seguidas da mesma letra na coluna não diferem entre si pelo teste Tukey, a 5\% de probabilidade. Diferença mínima significativa (DMS $=2,68)$.

O maior número de raízes por planta foi observado na colheita realizada aos dez meses pós-plantio (Figura 6) para todas as etnovariedades. Oliveira (2007) destaca que o número de raízes pode ser influenciado por condições ambientais, principalmente nos primeiros meses. A variação no número médio de raízes por 
planta entre as épocas de colheita em cada etnovariedade reflete expressões gênicas diferenciadas entre os genótipos, devido à diversidade genética existente entre os materiais avaliados.

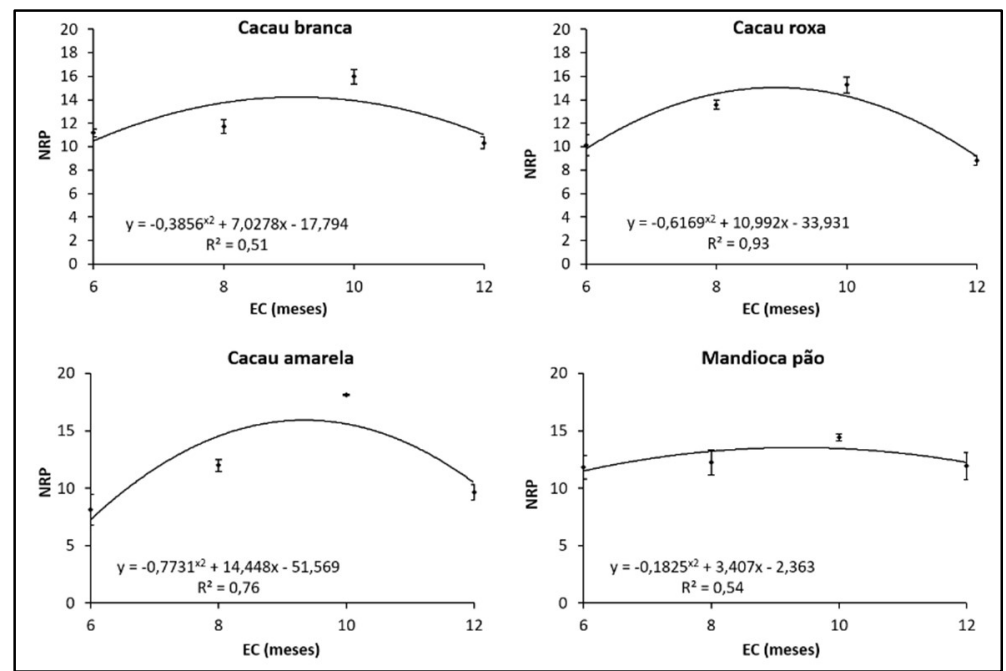

Figura 6: Número de raízes por planta (NRP) de quatro etnovariedades de mandioca em diferentes épocas de colheita (EC). $\mathbf{\Phi}$ : erro padrão da média.

Quanto ao comprimento médio das raízes tuberosas (CMR), as quatro etnovariedades apresentaram diferenças significativas entre as épocas de colheita (Tabela 7), sendo que as etnovariedades CR (aos seis meses) e MP (anos oito meses) foram as que apresentaram as maiores médias de comprimento (33,81 e 30,98 , respectivamente).

Tabela 7: Médias do comprimento médio das raízes $(\mathrm{cm})(\mathrm{CMR})$ de quatro etnovariedades de mandioca em épocas de colheita.

\begin{tabular}{|l|l|l|l|l|}
\hline \multirow{2}{*}{ Etnovariedades } & \multicolumn{4}{|l|}{ Épocas de colheita } \\
\cline { 2 - 5 } & $\mathbf{6}$ meses & $\mathbf{8}$ meses & $\mathbf{1 0}$ meses & $\mathbf{1 2}$ meses \\
\hline Cacau branca & $22,34 \mathrm{c}$ & $21,13 \mathrm{~b}$ & $20,47 \mathrm{~b}$ & $22,75 \mathrm{~b}$ \\
\hline Cacau roxa & $33,81 \mathrm{a}$ & $29,00 \mathrm{a}$ & $30,51 \mathrm{a}$ & $28,31 \mathrm{a}$ \\
\hline Cacau amarela & $21,98 \mathrm{c}$ & $20,76 \mathrm{~b}$ & $22,46 \mathrm{~b}$ & $22,04 \mathrm{~b}$ \\
\hline Mandioca pão & $27,78 \mathrm{~b}$ & $30,98 \mathrm{a}$ & $27,98 \mathrm{a}$ & $30,76 \mathrm{a}$ \\
\hline
\end{tabular}

Médias seguidas da mesma letra na coluna e maiúscula na linha não diferem entre si pelo teste Tukey, a $5 \%$ de probabilidade. Diferença mínima significativa (DMS = 3,32).

Analisando as épocas de colheita, verificou-se que as etnovariedades apresentaram variação ao longo do tempo, sendo que a Cacau branca produziu maiores raízes aos seis e doze meses, a Cacau roxa aos seis e dez meses, a Cacau amarela aos dez e doze meses e a Mandioca pão aos oito e doze meses (Figura 7).

Dentre as épocas avaliadas, a CR apresentou menor média de comprimento de raiz $(28,31 \mathrm{~cm})$ aos 12 meses pós-plantio, contudo, ainda foi semelhante ao relatado por Tiago (2016) que, para a mesma etnovariedade e aos 12 meses pós-plantio, obteve média inferior $(25,64 \mathrm{~cm})$ que a encontrada neste estudo. Conceição (1981) destaca que a variação encontrada no comprimento das raízes tuberosas de mandioca depende de alguns fatores como a variedade, as condições ambientais, o solo onde as raízes se desenvolveram, bem como a idade da planta. Neste estudo, como as quatro etnovariedades estavam nas mesmas condições de cultivo, está variação se deve à variabilidade genética das etnovariedades. 

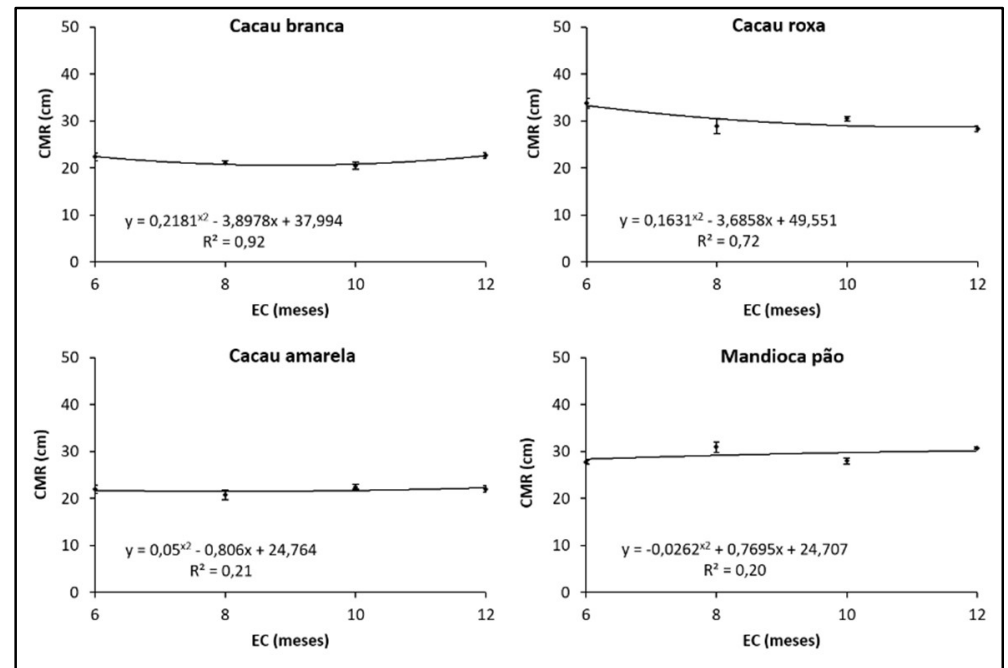

Figura 7: Comprimento médio das raízes (CMR) de quatro etnovariedades de mandioca em diferentes épocas de colheita (EC). \$: erro padrão da média.

O diâmetro médio das raízes variou de $9,38 \mathrm{~cm}$ para a CB aos seis meses até $13,60 \mathrm{~cm}$ para a MP aos doze meses pós-plantio (Tabela 8). Couto (2013) destaca que, quando comercializada, as raízes de mandioca preferidas pelos consumidores são aquelas com maiores diâmetros e que apresentam uniformidade quanto ao tamanho e forma. Neste estudo, a MP apresentou raízes com maiores diâmetros nas quatro épocas avaliadas, sugerindo que está tenha maior potencial produtivo que as demais.

Tabela 8: Diâmetro médio das raízes (cm) (DMR) de quatro etnovariedades de mandioca em épocas de colheita.

\begin{tabular}{|c|c|c|c|c|}
\hline \multirow[t]{2}{*}{ Etnovariedades } & \multicolumn{4}{|c|}{ Épocas de colheita } \\
\hline & 6 meses & 8 meses & 10 meses & 12 meses \\
\hline Cacau branca & $9,38 \mathrm{c}$ & $11,46 \mathrm{~b}$ & $10,56 \mathrm{c}$ & $10,52 \mathrm{c}$ \\
\hline Cacau roxa & $10,90 \mathrm{~b}$ & $12,04 \mathrm{~b}$ & $11,84 \mathrm{~b}$ & $12,15 b$ \\
\hline Cacau amarela & $9,90 \mathrm{c}$ & $10,52 \mathrm{c}$ & $10,48 \mathrm{c}$ & $10,27 \mathrm{c}$ \\
\hline Mandioca pão & $12,09 \mathrm{a}$ & $13,14 \mathrm{a}$ & 13,43 a & $13,60 \mathrm{a}$ \\
\hline
\end{tabular}

Médias seguidas da mesma letra na coluna e maiúscula na linha não diferem entre si pelo teste Tukey, a $5 \%$ de probabilidade. Diferença mínima significativa (DMS $=0,71$ ).

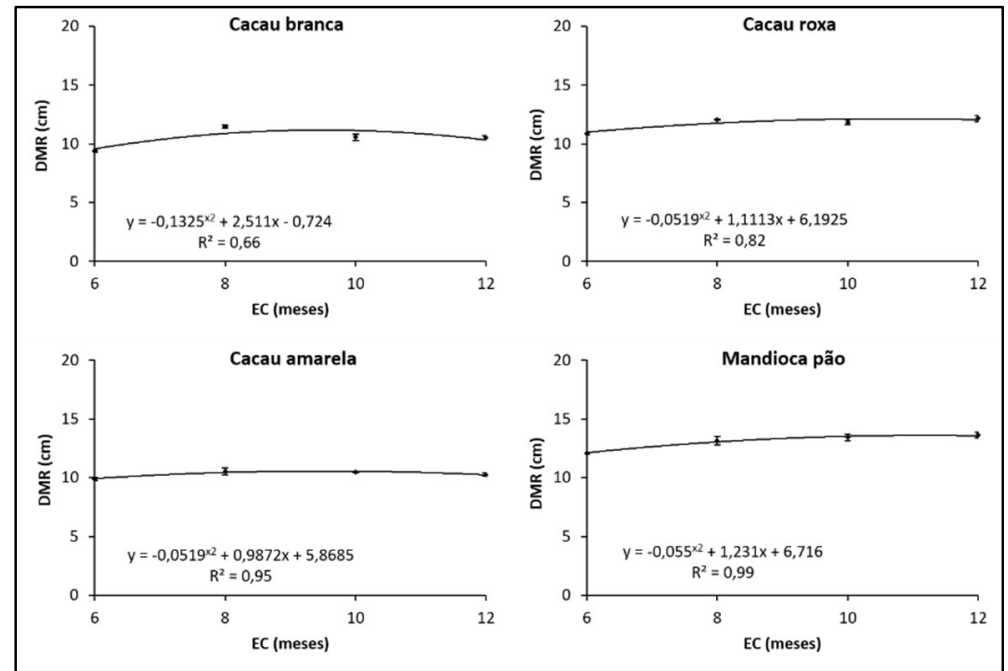

Figura 8: Diâmetro médio das raízes (DMR) de quatro etnovariedades de mandioca em diferentes épocas de colheita (EC). $\mathbf{\Phi}$ : erro padrão das médias.

A permanência das plantas no campo influenciou positivamente no diâmetro das raízes para todas as etnovariedades (Figura 8), apresentando nas últimas três avaliações (oito, dez e doze meses pós-plantio) as maiores médias. Este período também foi o momento em que foram verificadas maior produção de raízes, 
concordando com Williams (1974) que enfatiza que há correlação positiva e significativa entre o diâmetro e a produtividade de raízes tuberosas, ou seja, raízes com maiores diâmetros apresentam maior produtividade.

É possível observar que aos 12 meses pós-plantio ocorreu um incremento no diâmetro das raízes para as etnovariedades CR e MP, período este que coincide com o início do aumento da temperatura e precipitação pluvial (Figura 2). Tiago (2016), ao avaliar a produtividade dessas mesmas etnovariedades (CB, $\mathrm{CR}, \mathrm{CA}, \mathrm{MP})$, aos 12 meses pós-plantio, verificou maiores diâmetros de raízes $(25,34)$ para a etnovariedade MP e os menores diâmetros $(12,87)$ para a CA.

\section{CONCLUSÕES}

A época de colheita influenciou as características agronômicas das quatro etnovariedades avaliadas nas condições edafoclimáticas do município de Alta Floresta, Mato Grosso. A etnovariedade Mandioca pão apresentou maior produtividade de parte aérea e pode ser utilizada em cultivos que visam produção de massa verde para alimentação animal.

As etnovariedades Cacau roxa e Cacau amarela apresentaram pico de produtividade de raízes aos oito e dez meses pós-plantio, respectivamente. Já a Cacau branca e a Mandioca pão apresentam-se mais produtivas aos 12 meses, indicando que a permanência das plantas no campo proporcionou incremento na produtividade e diâmetro das raízes, além de maior índice de colheita e, portanto, são boas opções para o agricultor familiar mato-grossense.

\section{REFERÊNCIAS}

AGUIAR, B. E.; VALLE, T. L.; LORENZI, J. O.; KANTHACK, R. A. D.; MIRANDA FILHO, H.; GRANJA, N. P.. Efeito da densidade populacional e época de colheita na produção de raízes de mandioca de mesa. Bragantia, Campinas, v.70, n.3, p.561569, 2011. DOI: http://doi.org/10.1590/S0006$\underline{87052011005000010}$

ALBUQUERQUE, J. A. A.. Caracterização morfológica e agronômica de clones de mandioca cultivados no estado de Roraima. Dissertação (Mestrado em Fitotecnia) Universidade Federal de Viçosa, Viçosa, 2003.

ALBUQUERQUE, J. A. A.; SEDIYAMA, T.; SILVA, A. A.; SEDIYAMA, C. S.; ALVES, J. M. A.; NETO, F. A.. Caracterização morfológica e agronômica de clones de mandioca cultivados no Estado de Roraima. Revista Brasileira de Ciências Agrárias, Recife, v.4, n.4, p.388-394, 2009.

ALVARES, C. A.; STAPE, J. L.; SENTELHAS, P. C.; GONÇALVES, J. L. M.; SPAROVEK, G.. Koppen's climate classification map for Brazil. Meteorologische Zeitschrift, Stuttgart, v.22, n.6, p.711-728, 2013. DOI: http://doi.org/10.1127/09412948/2013/0507

ANDRADE, D. P.. Cultivares de mandioca de mesa e idades de colheita: avaliação agronômica e adequação ao processamento mínimo. Dissertação (Mestrado em Produção Vegetal) - Universidade Federal Rural de Pernambuco, Serra Talhada, 2013.
CARDOSO, E. S.; PEDRI, E. C. M.; YAMASHITA, O. M.. Políticas públicas, agricultura familiar e segurança alimentar $\mathrm{e}$ nutricional no Brasil e em Mato Grosso. Nativa, Sinop, v.6, n.2, p.124-133, 2018. DOI: http://dx.doi.org/10.31413/nativa.v6i2.4523

CARDOSO JUNIOR, N. S.; VIANA, A. E. S.; MATSUMOTO, S. N.; SEDIYAMA, T.; AMARAL, C. L. F.; PIRES, A. J. V.; RAMOS, P. A. S.. Efeito do nitrogênio sobre o teor de ácido cianídrico em plantas de mandioca. Acta Scientiarum Agronomy, Maringá, v.27, n.4, p.603-610, 2005. DOI:

https://doi.org/10.4025/actasciagron.v27i4.1307

CONCEIÇÃO, A. J. A.. A mandioca. São Paulo: Nobel, 1981.

COUTO, E. M.. Caracterização de cultivares de mandioca no semiárido mineiro em quatro épocas de colheita. Tese (Doutorado em Ciência dos Alimentos) - Universidade Federal de Lavras, Lavras, 2013.

CHIELLE, Z. G.; MORALES, C. F. G.; DORNELLES, M. A.; TEIXEIRA, C. D.; BECKER, L.. Desempenho agronômico de cultivares e seleção de mandioca em Rio Pardo, Rio Grande do Sul, Brasil. Pesquisa Agropecuária Gaúcha, Porto Alegre, v.15, n.1, p.53-56, 2009.

CRUZ, C. D.. Genes Software: extended and integrated with the R, Matlab and Selegen. Acta Scientiarum Agronomy, Maringá, v.38, n.4, p.547-552, 2016. DOI: http://doi.org/10.4025/actasciagron.v38i4.32629 
EMBRAPA. Empresa Brasileira de Pesquisa Agropecuária. Sistema Brasileiro de Classificação de Solos. Brasília: Embrapa Solos, 2013.

FAO. Food and Agriculture Organization of the United Nations. Produzir mais com menos: Mandioca, um guia para a intensificação sustentável da produção. São Paulo, 2013.

FIALHO, J. F.; VIEIRA, E. A.; SILVA, M. S.; PAULA-MORAES, S. V.; FUKUDA, W. M. G.; SANTOS FILHO, M. O. S.; SILVA, K. N.. Desempenho agronômico de variedades de mandioca de mesa no Distrito Federal. Revista Brasileira de Agrociência, Pelotas, v.15, n.1-4, p.31-35, 2009

FUKUDA, W. M. G.; GUEVARA, C. L.. Descritores morfológicos e agronômicos para a caracterização de mandioca (Manihot esculenta Crantz). Cruz das Almas: CNPMF, 1998.

\section{GONÇALVES, Y. S.. Fontes e doses de potássio na} produtividade qualidade da mandioca de mesa. Dissertação (Mestrado em Produção Vegetal) - Universidade Estadual do Norte Fluminense Darcy Ribeiro, Campos de Goytacazes, 2018.

LESSA, L. S; LEDO, C. A. S; SANTOS, V. S.. Effect of harvesting times on agronomic characteristics of industrial cassava genotypes. Revista Brasileira de Ciências Agrárias, Recife, v.14, n.2, e5647, 2019. DOI: http://dx.doi.org/10.5039/agraria.v14i2a5647

MELO, D. S.; CORRÊA, A. D.; MARCOS, F. C. A, SOUSA, R. V.; ABREU, C. M. P.; SANTOS, C. D.. Efeitos da farinha de folhas de mandioca sobre a peroxidação lipídica, o perfil lipídico sanguíneo e o peso do fígado de ratos. Ciência e Agrotecnologia, Lavras, v.31, n.2, p.420-428, 2007. DOI: https://doi.org/10.1590/S1413-70542007000200023

MORETO, A. L.; MIRANDA, M.; NEUBERT, E. O.. Adaptabilidade e estabilidade de genótipos de mandioca avaliados no Oeste de Santa Catarina. Agropecuária Catarinense, Florianópolis, v.29, n.3, p.60-65, 2016.

OLIVEIRA, S. P.. Efeito de poda e de épocas de colheita sobre características agronômicas de mandioca. Dissertação (Mestrado em Agronomia) - Universidade Estadual do Sudoeste da Bahia, Vitória da Conquista, 2007.

OLIVEIRA, N. T.; UCHÔA, S. C. P.; ALVES, J. M. A.; SEDIYAMA, T.; ALBUQUERQUE, J. A. A.; SOUZA, E. D.; MELVILLE, C. C. Ácido cianídrico em tecidos de mandioca em função da idade da planta e adubação nitrogenada. Pesquisa Agropecuária Brasileira, Brasília, v.47, n.10, p.1436-1442, 2012. DOI: http://doi.org/10.1590/S0100204X2012001000004

PEREIRA, L. C.; ÍTAVO, L. C. V.; MATEUS, R. G.; ROSA, M. O.; MACENA, I.; REIS NETO, J. F.; BARBOSA-FERREIRA, M.; CARVALHO, C. M. E.. Aspectos econômicos do uso da parte aérea in natura de mandioca (Manihot esculenta Crantz) para nutrição de cordeiros confinados e semiconfinados. Arquivo Brasileiro de Medicina Veterinária e Zootecnia,
Belo Horizonte, v.70, n.1, p.279-286, 2018. DOI: http://dx.doi.org/10.1590/1678-4162-9281

PESTANA, T. C.; CASTRO, G. H. F.. Potencial da rama de mandioca para uso na alimentação de ruminantes: Revisão. Publicações em Medicina Veterinária e Zootecnia, Maringá, v.9, n.10, p.457-466, 2015.

PONTE, C. M. A.. Épocas de colheita de variedades de mandioca. Dissertação (Mestrado em Agronomia) Universidade Estadual do Sudoeste da Bahia, Vitória da Conquista, 2008.

RIBEIRO, F. W.; RODRIGUES, C. C.; ARAÚJO, M. S.; SILVA, A. C.; MATOS, F. S.. Custos de produção e rentabilidade econômica do cultivo da mandioca em Goiás. Revista Verde de Agroecologia e Desenvolvimento Sustentável, Pombal, v.14, n.1, p.104-110, 2019. DOI:

http://dx.doi.org/10.18378/rvads.v14i1.5911

SOARES, M. R. S.. Características de variedades de mandioca em função de épocas de colheita. Dissertação (Mestrado em Agronomia) - Universidade Estadual do Sudoeste da Bahia, Vitória da Conquista, 2011.

SOARES, M. R. S.; NASCIMENTO, R. M.; VIANA, A. E. S.; CARDOSO, A. D.; MAGALHÃES, G. C.; FOGAÇA, J. J. L.. Componentes agronômicos qualitativos e caracterização morfológica de variedades de mandioca (Manihot esculenta Crantz) em seis épocas de colheita. Scientia Plena, São Cristóvão, v.13, n.6, p.1-12, 2017. DOI: http://dx.doi.org/10.14808/sci.plena.2017.061201

TEIXEIRA, P. R. G.; VIANA, A. E. S.; CARDOSO, A. D.; MOREIRA, G. L. P.; MATSUMOTO, S. N.; RAMOS, P. A. S.. Physical-chemical characteristics of sweet cassava varieties. Revista Brasileira de Ciências Agrárias, Recife, v.12, n.2, p.1981-0997, 2017. DOI: http://dx.doi.org/10.5039/agraria.v12i2a5433

TIAGO, A. V.. Diversidade genética e uso de etnovariedades de mandioca (Manihot esculenta Crantz) cultivadas em propriedades rurais no município de Alta Floresta, Norte do Estado de Mato Grosso. Dissertação (Mestrado em Biodiversidade e Agroecossistemas Amazônicos) Universidade do Estado de Mato Grosso Carlos Alberto Reyes Maldonado, Alta Floresta, 2016.

VÍTOR, L. A.; ARCHANGELO, E. R.; TEIXEIRA JÚNIOR, T.; SOARES, M. M.; VIEIRA, F. L.; MADEIRO, I. I. C.. Produtividade e qualidade das raízes da mandioca em função de diferentes épocas de colheita. Agri-Environmental Sciences, Palmas, v.1, n.2, p.67-72, 2016.

ZATARIM, M.; MAIOR, J. A. B.; VALLE, T. L.; CUPERTINO, J. L.. Avaliação da capacidade produtiva de genótipos de mandioca para indústria em Campo Grande, MS. Revista Raízes e Amidos Tropicais, São Paulo, v.3, p.1-4, 2007.

WILLIAMS, C. N.. Growth and Productivity of Tapioca (Manihot utilissima) IV. Development and Yield of Tubers. Experimental Agriculture, Campinas, v.10, p.9-16, 1974. DOI: http://doi.org/10.1017/\$0014479700006359

A CBPC - Companhia Brasileira de Produção Científica (CNPJ: 11.221.422/0001-03) detém os direitos materiais desta publicação. Os direitos referem-se à publicação do trabalho em qualquer parte do mundo, incluindo os direitos às renovações, expansões e disseminações da contribuição, bem como outros direitos subsidiários. Todos os trabalhos publicados eletronicamente poderão posteriormente ser publicados em coletâneas impressas sob coordenação da Sustenere Publishing, da Companhia Brasileira de Produção Científica e seus parceiros autorizados. Os (as) autores (as) preservam os direitos autorais, mas não têm permissão para a publicação da contribuição em outro meio, impresso ou digital, em português ou em tradução. 